\title{
AQUISIÇÃO INSTITUCIONAL DE PRODUTOS DA AGRICULTURA FAMILIAR:APONTAMENTOS SOBRE ASPECTOS OPERACIONAIS DA POLÍTICA PÚBLICA
}

Silvana Przybyzeski*

\begin{abstract}
Resumo
O reconhecimento conferido à agricultura familiar e a construção de políticas diferenciadas para um grupo social que até então não havia sido contemplado com ações específicas por parte do Poder Público certamente representa um importante avanço do modelo de Estado Democrático de Direito. O Programa de Aquisição de Alimentos (PAA) e o Programa Nacional de Alimentação Escolar (PNAE) fortalecem a agricultura familiar com mais uma alternativa de comercialização, diversificação e geração de renda, além de garantir a segurança alimentar e nutricional da população a quem os alimentos se destinam. No entanto, a política de facilitação das contratações públicas para o agricultor familiar pode não lograr êxito se for complexa em sua execução e não se atentar às peculiaridades do setor quanto à definição dos preços e a gestão dos riscos inerentes à produção agrícola. Diante disto, o presente trabalho se propõe a uma análise sobre as diretrizes para a definição dos preços contratuais nas aquisições públicas de produtos oriundos da agricultura familiar e a verificar se as hipóteses legais que autorizam a revisão contratual são condizentes com a realidade da produção agrícola, sujeita, por natureza, ao risco de oscilações significativas dos preços, de difícil previsão, a fim de contribuir para a reflexão do atual modelo e para a sustentabilidade das referidas políticas públicas.
\end{abstract}

Palavras-chave: Agricultura. Compras institucionais. Gestão de riscos.

\footnotetext{
* Mestre em Desenvolvimento Comunitário pela UNICENTRO. Procuradora do Município de Rio Azul e Professorade Direito. E-mail: silvanaprz@gmail.com
} 


\section{Introdução}

Com a emergência do conceito de Segurança Alimentar e Nutricional (SAN), a produção de alimentos pela agricultura familiar para sanar a fome da população tem sido alvo de muitos estudos que destacam estes agentes como uma poderosa ferramenta para garantir a segurança alimentar e nutricional das presentes e futuras gerações.

O papel econômico e social da agricultura familiar na produção de alimentos no Brasil se tornou evidente com os dados divulgados pelo último Censo Agropecuário, demonstrando que, em 2006, 84,4\% do total de estabelecimentos rurais do Brasil eram ocupados por agricultores ou empreendedores familiares (BRASIL, 2009), responsáveis pela produção dos principais produtos destinados à alimentação humana.

Neste cenário, políticas públicas alimentares como o Programa de Aquisição de Alimentos (PAA) e o Programa Nacional de Alimentação Escolar (PNAE) surgem como potenciais reintegradores desses componentes, por auxiliar no enfrentamento das problemáticas referentes à segurança alimentar e nutricional da população atendida e, ao mesmo tempo, por fortalecer a produção de alimentos, mediante a criação de mercados para os agricultores familiares, inclusive com potencial para fomentar práticas de gestão ambiental (TRICHES e SCHNEIDER, 2010).

Em 2009, com a entrada em vigor da Lei no 11.947 , teve início mais um movimento em favor da melhoria da qualidade nutricional da alimentação escolar. Com base nesta legislação, foi estabelecido que, no mínimo, 30\% do valor destinado pelo FNDE às entidades executoras do PNAE deveria ser utilizado para aquisição de alimentos provenientes da agricultura familiar.

Utilizando-se do poder de compra da Administração Pública, estes programas facilitam o acesso dos agricultores familiares ao mercado institucional por meio da possibilidade de contratação com dispensa de licitação, representando, assim, uma nova fonte de renda e emprego para o setor. Entretanto, apesar de os programas terem facilitado o acesso dos agricultores diminuindo o processo burocrático prévio à contratação pública, mantiveram a salvo os critérios de definição de preços e o modelo contratual da Lei no 8.666/93 para as contratações públicas em geral, sem se ater para as particularidades e hipossuficiências da produção agrícola familiar.

A produção agrícola apresenta características muito específicas se comparada a outros setores produtivos de uma economia, com destaque para a magnitude e a natureza dos riscos a que está sujeita, que precisam ser levados em consideração no momento da contratação.

Neste contexto, o presente estudo busca compreender as diretrizes para a definição dos preços contratuais nas aquisições públicas de 
produtos oriundos da agricultura familiar e verificar se as hipóteses legais que autorizam a revisão contratual são condizentes com a realidade da produção agrícola, sujeita, por natureza, ao risco de oscilações significativas dos preços, de difícil previsão.

A discussão é justificada pela importância que a agricultura familiar possui no Estado brasileiro, seja pela manutenção do homem no campo, seja pela produção de alimentos, fatos que impõe a compreensão da dinâmica das políticas públicas no contexto da agricultura familiar, para que, assim, seja possível verificar os aspectos positivos e negativos referentes às mesmas e refletir sobre possíveis aperfeiçoamentos.

Trata-se de uma pesquisa básica, que, por natureza, objetiva gerar conhecimentos novos úteis para a ciência (MANJINSKI, 2004), abordada de modo qualitativo, com o objetivo de descrever, com base em pesquisa bibliográfica, as linhas gerais do Programa de Aquisição de Alimentos (PAA) e do Programa Nacional de Alimentação Escolar (PNAE), especificamente no tocante à sistemática de contratação (critérios de definição dos preços, modo de execução e hipóteses legais de revisão de preços ou de gestão do risco) em paralelo com as particularidades do setor agrícola no que se refere à volatilidade de mercado.

Ao final, as informações teóricas são analisadas pelo modo dedutivo, ou seja, a partir de uma hipótese genérica, por intermédio da dedução, se chegar a uma conclusão, com vistas a provocar uma reflexão sobre o modelo atual e sobre possíveis alternativas para que o contrato administrativo se estabeleça de forma justa e transparente quanto à determinação dos preços e com efetiva redução de riscos.

\section{As políticas públicas de aquisição institucional de alimentos da agricultura familiar e sua operacionalização}

A partir do ano 1990 a agricultura familiar no Brasil começou a ter reconhecimento enquanto categoria social e produtiva (SOUZAESQUERDO e BERGAMASCO, 2014) e emergiu como componente da agenda das políticas públicas de desenvolvimento rural no país. De acordo com Silva, Dias e Silva (2014, p. 54), esta alteração é oriunda, principalmente, de um "conjunto de mudanças macroeconômicas ocorridas no período, relacionadas, sobretudo, à crise agrícola e às novas funções do meio rural"1, que afetaram de forma direta a política agrícola.

Grisa e Schneider (2014) destacam, ainda, as contribuições das diferentes organizaçõesda sociedade civil,taiscomoONGs, associações e cooperativas, provenientes do processo de democratização do país, que ampliaram a diversidade de formas de expressão em torno de novos projetos de desenvolvimento. De acordo com os autores, essas organizações se colocam, muitas vezes, na posição de mediação entre
1 Neste sentido, conferir BALSADI, OTAVIO VALENTIM. MUDANÇAS NO MEIO RURAL E DESAFIOS PARA O DESENVOLVIMENTO SUSTENTÁVEL. São Paulo Perspec., São Paulo , v. 15, n. 1, p. 155-165, Jan. 2001 . Disponível em: <http://www.scielo.br/scielo. php?script=sci_arttext\&pid=S010288392001000100017\&lng=en\&n $\mathrm{rm}=$ iso $>$. Acesso em 30 de julho de 2016. 
2 Os documentos oriundos da 31 ${ }^{\text {a }}$ Conferência Regional para a América Latina e Caribe, realizado pela Organização das Nações Unidas para a Alimentação e a Agricultura (FAO), podem ser consultados em sua íntegra no seguinte endereço http://www.fao.org/Unfao/Bodies/ RegConferences/Larc31/Index_ es.htm. o Estado e as práticas organizativas da população, passando a fazer parte de estruturas de gestão e governança das políticas públicas (SILVA, DIAS e SILVA, 2014).

Ressalta-se, ademais, o surgimento do conceito de crise alimentar definido pela Organização das Nações Unidas para a Alimentação e a Agricultura (FAO), sobretudo a partir da 31 ${ }^{\text {a }}$ Conferência Regional para a América Latina e Caribe, realizada em abril de 2010, no Panamá, que reconheceu a possível contribuição da agricultura familiar à segurança e à soberania alimentar da população e, considerando a heterogeneidade socioeconômica e territorial do desenvolvimento rural na região, recomendou aos países membros a necessidade de políticas de desenvolvimento rural que favoreçam uma maior equidade.

71. Foi reconhecida a acentuada heterogeneidade socioeconômica e territorial do desenvolvimento rural na região, originada nas diferenças de acesso a bens e mercados produtivos. Identificouse a necessidade de políticas de desenvolvimento rural com uma abordagem territorial que favoreça uma maior equidade.

72. Foi enfatizada a importância da agricultura familiar, tanto para a segurança alimentar e nutricional quanto para o alívio da pobreza, o crescimento econômico e a sustentabilidade ambiental, razão pela qual ela desempenha um papel estratégico na política de desenvolvimento.

73. Foi observado que o desenvolvimento da agricultura familiar requer não apenas o progresso da produção primária, mas também sua integração nas cadeias produtivas, além de apoio ao financiamento e comercialização. $\mathrm{O}$ desenvolvimento rural deve ser integrado ao desenvolvimento socioeconômico, favorecer a diversificação $\mathrm{da}$ produção agrícola, a expansão da agricultura suburbana e a promoção de atividades rurais não agrícolas. (FAO, 2010) ${ }^{2}$

Somente a partir do Censo Agropecuário realizado em 2006 (BRASIL, 2019), houve a inclusão deste segmento da agricultura na coleta dos dados censitários brasileiros, permitindo verificar sua importância no cenário da agricultura nacional. Foram identificados 5.175 .489 de estabelecimentos agropecuários no Brasil, ocupando área de 329,941 milhões de hectares. Destes, 4.367 .902 eram estabelecimentos familiares, representando $84,4 \%$ dos estabelecimentos agropecuários, ocupando área de 80,25 milhões de hectares, o que corresponde a $24,3 \%$ da área total, com média de 18,37 hectares.

O Censo Agropecuário de 2006 registrou ainda que 12,3 milhões de pessoas estavam vinculadas à agricultura familiar, o que representa $74,4 \%$ do pessoal ocupado, enquanto os estabelecimentos não familiares ocupavam 4,2 milhões de pessoas, correspondendo a $25,6 \%$ da mão de obra 
ocupada. Dispondo de apenas $24,3 \%$ da área total dos estabelecimentos agropecuários, esta categoria da agricultura foi responsável por $38 \%$ do valor bruto da produção dos estabelecimentos em 2006.

Apesar da importância da agricultura familiar brasileira, historicamente este setor foi excluído das políticas públicas, com o direcionamento da maioria dos recursos estatais reservados à agricultura para as grandes propriedades monocultoras de produtos destinados, em sua grande parte, à exportação. "Os estímulos recebidos por parte do Estado asseguraram a modernização e a reprodução da grande propriedade monocultora, fazendo com que a agricultura familiar ocupasse um lugar subalterno na sociedade" (SOUZA-ESQUERDO e BERGAMASCO, 2014, p. 206).

É neste contexto que surgem, no País, nos últimos anos, políticas públicas diferenciadas que inserem a temática do desenvolvimento rural na agenda governamental, tendo a agricultura familiar como foco das intervenções.

O marco de entrada no cenário político foi o Programa Nacional de Fortalecimento da Agricultura Familiar (Pronaf), programa de crédito instituído em 1996 que permite acesso a recursos financeiros para o desenvolvimento da agricultura familiar (BRASIL, 2019).

A operacionalização deste programa exigiu uma definição legal da categoria "agricultor familiar" ou "empreendedor familiar rural", o que foi realizado pela Lei no $11.326 / 2006$, a qual os define em seu art. $3^{\circ}$ como sendo aquele que pratica atividades no meio rural atendendo, simultaneamente, aos seguintes requisitos: a) não detenha, a qualquer título, área maior do que 4 (quatro) módulos fiscais; b) utilize predominantemente mão-de-obra da própria família nas atividades econômicas do seu estabelecimento ou empreendimento; c) tenha percentual mínimo da renda familiar originada de atividades econômicas do seu estabelecimento ou empreendimento, na forma definida pelo Poder Executivo; e d) dirija seu estabelecimento ou empreendimento com sua família.

Desde então, outras políticas públicas com diversos objetos (crédito rural, assistência técnica, infraestrutura, acesso aos mercados, entre outros) foram desenvolvidas direcionadas à agricultura familiar e, conforme assinalado por Arzeno e Ponce (2014), se revelam um marco no discurso que prega a construção de um novo modelo de desenvolvimento para fins de combate à pobreza e à desigualdade econômica, levando em consideração um setor que foi e, de certa forma, ainda tem sido, amplamente prejudicado pelas políticas neoliberais.

Neste sentido, destacam-se o Pronaf, a Assistência Técnica e Extensão Rural (ATER), o Programa Nacional de Crédito Fundiário (PNCF), cujo objetivo principal é financiar a aquisição de imóveis rurais não passíveis 
de desapropriação, o Sistema Unificado de Atenção à Sanidade Animal (SUASA), que legaliza e acelera a implantação de novas agroindústrias e o Seguro-Safra, que serve de garantia aos agricultores familiares em caso de perda de produção causada por problemas climáticos, como a seca, por exemplo, dentre outros.

O presente ensaio, contudo, se limita a analisar as políticas públicas de comercialização e acesso aos mercados, em especial o mercado institucional, "uma das possibilidades mais acessíveis de comercialização da produção e fortalecimento da agricultora familiar" (GRISA e SCHNEIDER, 2014, p. 138), mas que ao mesmo tempo tem se tornado um desafio, cobrando do Poder Público e das famílias agricultoras formas de organização e gestão cada vez mais rápidas e adequadas. Conforme destacado por Schmitt e Guimarães,

A comercialização de produtos da agricultura familiar por meio do mercado institucional é um fenômeno relativamente recente no país e provoca o surgimento da discussão acerca do papel do Estado na reestruturação dos circuitos de produção, distribuição e consumo de alimentos com base em princípios de justiça social e sustentabilidade ambiental. (SCHMITT e GUIMARÃES, 2008, p. 8).

O acesso a mercados pode ser dividido em duas categorias: o mercado institucional e o mercado privado. No mercado institucional, destacam-se o Programa Nacional de Alimentação Escolar (PNAE) e o Programa de Aquisição de Alimentos (PAA) e no mercado privado, as feiras e vendas diretas a estabelecimentos comerciais atacadistas.

O Programa de Aquisição de Alimentos (PAA) foi criado em 2003 pelo Governo Federal como uma das ações do Programa Fome Zero e tem como finalidade o enfrentamento da fome e da pobreza e o fortalecimento da agricultura familiar por meio de mecanismos de comercialização que favorecem a aquisição direta de produtos de agricultores familiares ou de suas organizações, estimulando os processos de agregação de valor à produção (BRASIL, s/d).

O PAA foi instituído pelo Art. 19 da Lei no 10.696/2003 e está regulamentado pelo Decreto $\mathrm{n}^{\circ} 7.775 / 2012$, se dividindo em seis modalidades: doação simultânea, compra direta, formação de estoques, PAA leite, compra institucional e aquisição de sementes, que são executadas diretamente pela Companhia Nacional de Abastecimento (CONAB), podendo ser desempenhadas também por estados e municípios conveniados com o Governo Federal ou com recursos próprios.

Desta forma, o PAA se operacionaliza de dois modos: uma parte dos alimentos é adquirida pelo governo diretamente dos agricultores familiares para a doação às entidades da rede socioassistencial (restaurantes populares, bancos de alimentos e cozinhas comunitárias, entre outros) e outra parte 
é adquirida pelas próprias organizações da agricultura familiar para formação de estoques próprios. Este trabalho se atém ao primeiro modo de operacionalização do programa, nas modalidades doação simultânea e compra institucional.

Conforme disposto no Decreto no 7.775/2012 (BRASIL, 2012), a modalidade compra com doação simultânea consiste na aquisição de alimentos diversos da agricultura familiar e doação simultânea às entidades da rede socioassistencial, aos equipamentos públicos de alimentação e nutrição e à rede pública e filantrópica de ensino, com o objetivo de atender demandas locais de suplementação alimentar de pessoas em situação de insegurança alimentar e nutricional. A modalidade compra institucional, por sua vez, consiste na compra da agricultura familiar para o atendimento de demandas de consumo de alimentos, por parte do próprio órgão comprador.

O Programa Nacional de Alimentação Escolar (PNAE), por sua vez, teve sua origem no início da década de 40 e, em 2009, foi aperfeiçoado pela Lei no11.947, que prevê, em seu artigo 14, o uso de no mínimo 30\% dos recursos repassados pelo Fundo Nacional de Desenvolvimento da Educação (FNDE) para a alimentação escolar, na compra de alimentos da agricultura familiar para serem servidos nas escolas da rede pública de ensino.

O PNAE é considerado o maior programa de suplementação alimentar da América Latina, tendo em vista o tempo de atuação, a continuidade, o compromisso constitucional desde 1988, o caráter universal, o número de alunos atendidos e o volume de investimentos já realizados (LIBERMANN e BERTOLINI, 2015).

Inicialmente, a Lei no $11.947 / 2009$ previa como o limite máximo de venda dos produtos da agricultura familiar o valor de $\mathrm{R} \$ 9.000,00$ por DAP, por ano. Em julho de 2012 esse limite máximo foi aumentado através da Resolução no 25 para $\mathrm{R} \$ 20.000,00$ por DAP, por ano.

Atualmente a Lei no 11.947/2009 encontra-se regulamentada pela Resolução no 4/2015, do Conselho Deliberativo do FNDE, que descreve os procedimentos operacionais que devem ser observados para venda dos produtos oriundos da agricultura familiar à Administração Pública, denominada Entidade Executora.

Com o PAA e o PNAE, o Estado passou a atuar pautado nos conceitos de Segurança Alimentar e Nutricional sustentável (SAN), assentando-se em dois componentes básicos, conforme destacado por Triches e Schneider (2010): o componente alimentar, relacionado à produção, disponibilidade, comercialização e acesso ao alimento, e o componente nutricional, relacionado às práticas alimentares e à utilização biológica do alimento, e, portanto, ao estado de nutrição da população. 


\subsection{Sistemática de contratação nas aquisiçôes públicas e as hipóteses de revisão de preços dos contratos}

Em ambos os programas, a compra institucional pode ser feita com dispensa de licitação, precedida apenas de chamada pública previamente disponibilizada a todos os interessados. Nos termos do parágrafo único do Decreto no 7.775/2012, o edital da chamada pública deve conter no mínimo: a descrição do objeto a ser contratado; quantidade e especificação dos produtos; local da entrega; critérios de seleção dos beneficiários ou organizações fornecedoras; condições contratuais e relação de documentos necessários para habilitação (BRASIL, 2012).

No edital da chamada pública também devem constar obrigatoriamente os preços máximos que serão pagos ao agricultor familiar, empreendedor familiar rural e/ou suas organizações pela venda do gênero alimentício, os quais, ressalta-se, devem (ou pelo menos deveriam) ser compatíveis com os vigentes no mercado, em âmbito local ou regional.

No PAA, os parâmetros para definição dos preços de referência de aquisição de alimentos constam na Resolução GGPAA no 39 de 26/01/2010 e para o PNAE, na Resolução CD/FNDE n 26 de 17 de junho de 2013. Em ambos os documentos a sistemática de definição do preço de referência é semelhante, sendo definido pela Entidade Executora pela média praticada pelo mercado na época do ajuste.

“O preço de aquisição será o preço médio pesquisado por, no mínimo, três mercados em âmbito local, priorizando a feira do produtor da agricultura familiar, quando houver, acrescido dos insumos exigidos no edital de chamada pública, tais como despesas com frete, embalagens, encargos e quaisquer outros necessários para o fornecimento do produto" (BRASIL, 2013).

Após a assinatura dos instrumentos contratuais e a devida publicidade dos mesmos, a relação entre o Poder Público e agricultores familiares passa a ser regida pela Lei Geral das Contratações Públicas, a Lei no 8.666/93, aplicando-se todas as prerrogativas da Administração e cláusulas exorbitantes comuns aos contratos administrativos.

Os traços peculiares ao regime do contrato administrativo giram em torno da supremacia de uma das partes, que, a seu turno, procede da prevalência do interesse público sobre os interesses particulares. Esta supremacia vai expressar-se tanto na possibilidade de instabilizar a relação, quanto na autoridade do contratante público. (MELLO, 1996, p. 629).

Em razão da destinação do objeto dos contratos para aquisição institucional de alimentos (merenda escolar, entidades assistenciais, entre 
outros), a execução dos contratos geralmente se dá de forma sucessiva ou continuada, em que os produtos são adquiridos dos agricultores familiares de forma parcelada no decorrer do ano, conforme cardápio e necessidade da instituição adquirente.

De acordo com Venosa (2014) nos contratos de execução sucessiva as relações das partes desenvolvem-se por um período mais ou menos longo, devido à própria natureza da relação. De fato, são muito raros os casos de compra institucional, principalmente no âmbito do PNAE, em que o Poder Público realiza a contratação e adquire todo o quantitativo de forma imediata e em uma única parcela.

Nos contratos de trato sucessivo, caso as condições originárias contratadas se alterarem de modo a influírem juridicamente e justificadamente no cumprimento de suas cláusulas, pode ser aplicada a teoria da imprevisão, que consiste no reconhecimento de que eventos novos, imprevistos ou imprevisíveis pelas partes e a elas não imputáveis, refletindo sobre a economia ou a execução do contrato, autorizam sua revisão, para ajustá-lo às circunstâncias supervenientes mantendo o equilíbrio econômico financeiro do contrato (MEIRELLES, 2004).

É sabido que durante a execução do contrato administrativo podem ocorrer determinados eventos capazes de afetar o equilíbrio econômico ajustado entre a Administração Pública e o particular e nesses casos, uma vez presentes os requisitos legais, deve a equação econômico-financeira ser reequilibrada, sob pena de haver enriquecimento ilícito por parte de um dos contratantes.

Trata-se da aplicação da velha cláusula rebus sic standibus aos contratos administrativos, a exemplo do que ocorre nos ajustes privados, a fim de que sua execução se realize sem a ruína do contratado, criando ônus excessivo para uma das partes em detrimento da outra (MEIRELLES, 2004).

A aplicação da cláusula rebus sic standibus não se confunde com o reajuste de preços previsto na Lei 10.192/2001 e é autorizada pela Lei ${ }^{\circ}$ 8.666/93 na alínea "d", do inciso II do art. 65, ao lado dos motivos de força maior, caso fortuito ou fato do príncipe, como causa legitimadora das alterações contratuais bilaterais, para restabelecer a relação que as partes pactuaram inicialmente entre os encargos do contratado e a retribuição da administração para a justa remuneração, na hipótese de sobrevirem fatos imprevisíveis, ou previsíveis, porém, de consequências incalculáveis, retardadores ou impeditivos da execução do ajustado, configurando álea econômica extraordinária e extracontratual.

Ressalta-se, ainda, que de acordo com a jurisprudência dos Tribunais de Justiça e do Tribunal de Contas da União, as flutuações econômicas e de mercado não configuram, por si só, motivo hábil para invocação da regra excepcional para alterar o contrato, pois representam um risco certo e conhecido pelo empreendedor no momento da contratação. 
Portanto, após celebrado o contrato para a compra institucional de alimentos entre o agricultor familiar e o Poder Público, aplica-se o princípio pacta sun servanta, que diz que os contratos devem ser cumpridos, autorizada a revisão nos preços apenas nos casos em que comprovadamente sobrevirem fatos imprevisíveis, ou previsíveis, porém, de consequências incalculáveis, retardadores ou impeditivos da execução do ajustado.

\section{Riscos de preços no mercado de produtos agrícolas}

A agricultura, ou mais precisamente, o processo produtivo da agricultura apresenta características muito específicas se comparada a outros setores produtivos de uma economia. De acordo com Burgo (2005), uma das características mais marcantes deste setor é a magnitude e a natureza dos riscos a que está sujeita, riscos estes que não ocorrem comumente na produção industrial, por exemplo.

Os produtos agrícolas, independentemente se produzidos por grandes produtores ou pelo agricultor ou empreendedor familiar, estão expostos a diversos riscos e incertezas, inerentes à própria atividade rural, que impactam sobre os custos de produção e sobre a lucratividade dos negócios, afetando diretamente a renda do produtor rural.

A produção oriunda da agricultura familiar é em sua maioria comercializada "in natura", composta geralmente por hortifrutigranjeiros, os quais, pela sua própria natureza, são sazonais, perecíveis e se revelam um dos mais vulneráveis às oscilações de preço.

De acordo com Waquil, Miele e Schultz (2010), os riscos relacionados às especificidades da atividade rural e podem ser divididos em três tipos:

- riscos relacionados à produção: oriundos das condições climáticas adversas, da incidência de pragas e doenças nas lavouras e animais, do manejo inadequado dos cultivos e das criações, etc.;

- riscos relacionados ao crédito: oriundos da inexistência de linhas específicas de financiamento, dos juros altos, dos valores insuficientes para financiamento dos custos operacionais de produção, da incapacidade e da falta de condições de pagamento, etc.; e - riscos relacionados aos preços: oriundos dos movimentos de preços no mercado devido aos deslocamentos da oferta e/ou da demanda dos produtos agrícolas.

Uma das principais incertezas, considerando-se que os produtores não possuem nenhuma ou pouca possibilidade de influência, está relacionada ao risco de preços (WAQUIL, MIELE E SCHULTZ, 2010). De acordo com Pagliuca et. al. (2015), no setor hortifrutícola, a formação dos preços não escapa da lei de oferta e demanda, sendo a oferta é a variável que mais determina as oscilações dos preços. 
Quando a disponibilidade de um produto é alta, a pressão sobre suas cotações é forte. Assim, para que se consigam bons resultados com a venda dos hortifrutícolas, o desafio é evitar a comercialização em períodos de pico de safra. Para tanto, o produtor precisa manejar muitos fatores agronômicos, requerendo que tenha elevado conhecimento sobre as práticas a serem aplicadas. Caso se aventure ao risco climático/agronômico, pode ter resultados desastrosos. (PAGLIUCA; et. al., 2015, p.18)

Desta forma, além de enfrentar os infortúnios inerentes à produção e ao financiamento dos custos operacionais das atividades, o produtor rural tem o desafio com relação às expectativas futuras referentes às cotações dos preços dos produtos agrícolas, influenciados por tendências históricas, sazonalidades da produção e movimentos especulativos causadores de oscilações significativas dos preços (WAQUIL, MIELE E SCHULTZ, 2010), oscilações estas de difícil previsão e que dificultam sobremaneira o planejamento da produção e da comercialização bem como a tomada de decisão por parte dos agricultores, sob o risco de rompimentos de contratos.

Conforme anotam Faulin e Azevedo (2003), na agricultura familiar estas incertezas se tornam ainda maiores, em razão do limitado acesso dos produtores familiares às informações sobre o mercado, as quais estão em posse dos atacadistas e varejistas, e à falta de conhecimento suficiente à elaboração de um planejamento estratégico para a comercialização.

Como alternativa para minimizar as incertezas associadas à volatilidade de preços e o problema de possíveis rompimentos de contratos, o setor agrícola adota alguns mecanismos de operação no mercado, eliminando variações adversas mediante o estabelecimento de contratos futuros, ou compromissos de compra e venda futura.

No contrato futuro, as partes ficam obrigadas a comprar ou vender o objeto da negociação por meio de contratos padronizados e disponíveis no mercado de derivativos (bolsa), pelo preço negociado em pregão (WAQUIL, MIELE E SCHULTZ, 2010). Estes contratos também são denominados de "derivativos" porque derivam de outros contratos ou mercados físicos, onde os preços são definidos por um agente estranho às partes, tal como previsto no artigo 485 do Código Civil de 2002.

No Brasil, atualmente, os contratos futuros são negociados na bolsa de Mercadorias e Futuros (BM\&FBovespa), fundada em 1991, na cidade de São Paulo, que fornece cotação para contratos futuros agropecuários de boi gordo, etanol, soja, milho e café.

O contrato futuro difere do contrato a termo por não estabelecer previamente o preço, mas apenas a qualidade, quantidade, data e local de entrega futura dos produtos. No contrato a termo, independentemente do que ocorrer com os preços dos produtos no mercado (baixa ou alta), o vendedor e o comprador terão que honrar o compromisso assumido em contrato (WAQUIL, MIELE E SCHULTZ, 2010). 
De acordo com Marques e Mello (1999), o mercado futuro permite um melhor planejamento, diminuição dos custos de transação e aumento na competitividade das cadeias. Já nos dizeres de Costa (2008),

(...) este modelo aprimorou o mercado a termo no que diz respeito a algumas características que o aproximam do modelo de competição perfeita, como homogeneidade do produto, otimização do mercado e informações transparentes, permitindo, assim que os preços possam se ajustar conforme as leis de oferta e demanda. (COSTA, 2008, p. 20)

Ainda de acordo com Costa (2008), o mercado futuro também promove a transferência de risco de preços entre os participantes da negociação, proporcionando, assim, a sua redução, além de ter maior transparência na determinação dos preços, favorecendo o processo de disseminação de informações.

\section{1. (In) segurança jurídica e a (in) efetividade da política pública}

Conforme anota Celso Antonio Bandeira de Mello (1996), a garantia do contratado ao equilíbrio econômico-financeiro do contrato administrativo não pode ser afetada nem mesmo por lei. A manutenção das condições efetivas da proposta decorre do art. 37 da Constituição da República de 1988 e do princípio da segurança jurídica das relações, que tem como objetivo facilitar a coordenação das interações humanas reduzindo a incerteza que as cerca, tanto em relação às interações já consumadas quanto aos efeitos jurídicos futuros das condutas e relações que são decididas no presente (PINHEIRO, 2005).

A segurança jurídica também objetiva permitir aos indivíduos programar, em bases razoáveis de previsibilidade, suas expectativas em relação às implicações futuras de sua atuação jurídica. No que tange às relações jurídicas de cunho econômico, em especial, deve a norma dar ao indivíduo a possibilidade de calcular, com alguma previsibilidade, as consequências de suas ações. (PINHEIRO, 2005, p. 2)

Trabalhar com o risco na produção agrícola é um desafio até para os produtores mais experientes no mercado, quiçá então para o agricultor familiar, que tem uma pequena produção, geralmente para a própria subsistência, e raramente dispõe de conhecimentos, tecnologia para driblar os riscos da produção (produção em estufas fechadas, mecanismos de irrigação, entre outros) ou recursos para suportar oscilações de mercado.

Desta forma, embora os critérios de definição de preços de referência das chamadas públicas para aquisição de produtos oriundos da agricultura familiar presentes nas Resoluções GGPAA no 39/2010 e CD/FNDE 
$n^{\circ} 26 / 2013$ sejam adequados, estando inclusive em conformidade com o entendimento do Tribunal de Contas da União (TCU) sobre definição de preços máximos em processos de compras públicas, verifica-se que pode não ser a forma mais apropriada para a definição de preços contratuais de produtos agrícolas, principalmente pelo modo que a maioria destes contratos são executados, ou seja, de forma continuada ou sucessiva.

Ressalta-se, ainda, que os preços de referência são definidos pelo próprio Poder Público adquirente na fase interna do processo e o contrato é o típico contrato de adesão da Administração Pública, sem oportunidade para que o agricultor familiar discuta os preços ou cláusulas. Mesmo que o agricultor saiba dos riscos e das possíveis variações futuras do mercado, não lhe resta outra alternativa a não ser aderir ao instrumento, caso queira garantir a venda de sua produção.

Ademais, a volatilidade e instabilidade do mercado agrícola pode fazer com que a própria Administração Pública assuma os riscos de pagar preços mais caros do que os praticados pelo mercado, uma vez que há o risco de dois cenários diferentes no mercado no decorrer da contratação.

Por exemplo: em janeiro de 2019, o preço acordado entre as partes (agricultor familiar e Poder Público) para entrega de tomates para a merenda escolar no decorrer do ano de 2019 foi de $\mathrm{R} \$ 3,70$ por kg. Podem ser supostos dois cenários em junho de 2019: $1^{\circ}$ cenário: o preço do tomate caiu para $\mathrm{R} \$ 2,90$ o kg. Neste cenário, o produtor estará em situação confortável, com o direito de receber um preço bem acima do praticado no mercado. Por outro lado, a Administração Pública pagará 21,60\% a mais pelo $\mathrm{kg}$ de tomate e $\mathbf{2}^{\mathbf{0}}$ cenário: o preço do tomate aumentou para $\mathrm{R} \$$ 5,00. Neste segundo cenário a Administração Pública compradora está em situação confortável, com o direito de pagar um preço bem abaixo do praticado no mercado. Por outro lado, o produtor, ao deixar de ganhar 35\% a mais pelo $\mathrm{kg}$ de tomate, oferecendo risco ao sistema com a possibilidade de rompimento do contrato, já que existe a possibilidade de vender o tomate no mercado local por $\mathrm{R} \$ 5,00 \mathrm{o} \mathrm{kg}$.

É neste aspecto que surge a discussão proposta por este ensaio, de que embora sejam indiscutíveis os avanços proporcionados pelas políticas de aquisição institucional de alimentos produzidos pela agricultura familiar, é preciso repensar os mecanismos de operacionalização a fim de que não desestimule a participação dos agricultores familiares e nem provoque a própria inefetividade do Programa.

Uma alternativa a ser melhor estudada é a viabilidade de utilização de preços de referência com base na cotação diária elaborada pela CEASA (Central de Abastecimento), presente nas principais concentrações urbanas do país.

Nesta forma de estipulação de preços o produtor deixaria de ganhar caso os preços caíssem e deixaria de perder caso os preços aumentassem 
(os movimentos nos preços serão compensados pelos ajustes diários). Da mesma forma, a Administração Pública deixaria de perder caso os preços caíssem e deixaria de ganhar caso os preços aumentassem. Muitos produtores podem entender que deixar de ganhar é perder, mas o fundamental para os negócios agropecuários é a alteração das características de risco de preço da produção agrícola.

\section{Considerações finais}

O novo e atual modelo político, plural e democrático, inaugurado com a Constituição de 1888, vincula a atuação da Administração Pública ao atendimento de uma série de objetivos axiológicos. Nesse sentido, emergiu o conceito de licitação sustentável, mediante a inserção de critérios sociais, ambientais e econômicos nas contratações públicas.

De modo adjacente a aprovação das Leis 10.696/2003 e 11.947/2009 reconhecendo o papel econômico e social da agricultura familiar na produção de alimentos no Brasil (SOUZA-ESQUERDO e BERGAMASCO, 2014) e permitindo uma parceria entre a Administração Pública e os agricultores familiares na aquisição pública de alimentos, certamente pode representar importante avanço para o fortalecimento da agricultura familiar, com mais uma alternativa de comercialização, diversificação e geração de renda, além de fomento ao desenvolvimento da economia local com o incentivo da cadeia da produção à comercialização e a geração de emprego e renda.

Sem embargo disso, o tradicional Direito Administrativo, sobretudo a seara dos contratos administrativos, produto do liberalismo econômico do século XIX (GRAU,2002), apresenta um relativo descompasso com o modelo jurídico do Estado Constitucional, sobretudo no que se refere às compras institucionais para a efetivação de políticas para a agricultura familiar.

Pode se concluir com o presente trabalho que a legislação brasileira reserva um depurado cuidado com a segurança da Administração Pública ao celebrar contratos administrativos, o que sem dúvidas é relevante. Todavia, à semelhança do que ocorre nas demais contratações públicas, pouco se preocupa com a segurança que o direito precisa emprestar e assegurar aos particulares nas suas relações com o Estado, o que se agrava, sobremodo, nas peculiaridades da produção agrícola, exposta a diversos riscos e incertezas inerentes, que impactam sobre os custos de produção e sobre a lucratividade dos negócios, afetando diretamente a renda do produtor rural, exigindo uma atuação especial do Estado.

Nessa linha de raciocínio, o exame de mecanismos que garantam o comércio justo (fair trade) nas aquisições públicas, congregando responsabilidade social, sustentabilidade e competitividade para a agricultura familiar, para o fim de atingir os fins estatais delimitados pela Constituição passa a ter grande relevância para o Direito. 
Partindo da hipótese de que a política de facilitação das contratações públicas para o agricultor familiar não terá êxito se continuar complexa em sua execução, a discussão proposta por este ensaio propõe uma reflexão sobre os mecanismos de operacionalização do programa, especialmente com relação à definição de preços, a fim de que não represente sua própria falência e nem cause a inefetividade da política pública.

\section{Referências}

ARZENO, Mariana; PONCE, Mariana. Las contradicciones de las políticas públicas: desarrollo territorial rural en la provincia de Misiones, Argentina. CDC, Caracas, v. 31, n. 85, p. 69-93, abr. 2014. Disponível em: <http://www.scielo.org. ve/scielo.php?script=sci_arttext\&pid=S1012-25082014000100004\&lng=es\&nrm =iso>. Acesso em 14 de julho de 2019.

BALSADI, OTAVIO VALENTIM. Mudanças no meio rural e desafios para o desenvolvimento sustentável. São Paulo Perspec., São Paulo , v. 15, n. 1, p. 155-165, Jan. 2001. Disponível em: <http://www.scielo.br/scielo.php?script=sci_ arttext\&pid=S0102-88392001000100017\&lng=en\&nrm=iso >. Acesso em 30 de julho de 2019.

BRASIL.IBGE. Censo Agropecuário 2006 - Agricultura Familiar, Primeiros Resultados. Rio de Janeiro: IBGE. 2009. Disponível em: https://www.ibge.gov.br/. Acesso em 25 de julho de 2019.

BRASIL. Decreto no 7.775, de 04 de julho de 2012. Regulamenta o art. 19 da Lei no 10.696, de 2 de julho de 2003, que institui o Programa de Aquisição de Alimentos, e o Capítulo III da Lei no 12.512, de 14 de outubro de 2011, e dá outras providências. Brasília, DF: Presidência da República, [2019]. Disponível em: http://www.planalto.gov.br/ccivil_03/_Ato2011-2014/2012/Decreto/D7775. htm. Acesso em: 15 de junho de 2019.

BRASIL. Lei no 10.696, de 02 de julho de 2003. Dispõe sobre a repactuação e o alongamento de dívidas oriundas de operações de crédito rural, e dá outras providências. Brasília, DF: Presidência da República, [2019]. Disponível em: http://www.planalto.gov.br/ccivil_03/LEIS/2003/L10.696.htm. Acesso em: 15 de junho de 2019.

BRASIL. Lei no 11.947, de 16 de junho de 2009. Dispõe sobre o atendimento da alimentação escolar e do Programa Dinheiro Direto na Escola aos alunos da educação básica. Brasília, DF: Presidência da República, [2019]. Disponível em: http://www.planalto.gov.br/ccivil_03/_Ato2007-2010/2009/Lei/L11947.htm. Acesso em: 15 de junho de 2019.

BRASIL. Ministério da Educação. Resolução/CD/FNDE no 26, de 17 de junho de 2013. Dispõe sobre o atendimento da alimentação escolar aos alunos da educação básica no âmbito do Programa Nacional de Alimentação Escolar - PNAE. Brasília, DF: Presidência da República, [2018]. Disponível em: https://www. fnde.gov.br/index.php/acesso-a-informacao/institucional/legislacao/item/4620resolu\%C3\%A7\%C3\%A3o-cd-fnde-n\%C2\%BA-26,-de-17-de-junho-de-2013. Acesso em 16 de maio de 2018.

BRASIL. Ministério do Desenvolvimento Social. Resolução GGPAA no 39 de 26/01/2010. Dispõe sobre os preços de referência para a aquisição dos produtos 
da agricultura familiar sob as modalidades Compra da Agricultura Familiar com Doação Simultânea e Compra Direta Local da Agricultura Familiar com Doação Simultânea. Brasília, DF: Presidência da República, [2018]. Disponível em: http://www.mds.gov.br/webarquivos/legislacao/seguranca_alimentar/resolucoes/ resolucaoggpaan39de26janeiro2010.pdf. Acesso em 16 de maio de 2018.

BURGO, Marcelo Nery. Caracterização espacial dos riscos na agricultura e implicações para o desenvolvimento de instrumentos para o seu gerenciamento. Dissertação de Mestrado apresentada à Escola Superior de Agricultura "Luiz de Queiroz". Universidade de São Paulo, Piracicaba-SP, 2005.

COSTA, Alexandre Alvesi. Condições para a implantação do contrato futuro de arroz no Brasil. Dissertação de Mestrado apresentada ao Programa de Pós Graduação em Economia Aplicada. Universidade Federal de Viçosa. Viçosa-MG, 2008.

FAO. Seguridad Alimentaria como Estrategia de Desarrollo Rural.28 ${ }^{\text {a Conferência }}$ Regional de la FAO para América Latina y el Caribe. Guatemala, Abril de 2004. Disponível em: http://www.fao.org/. Acesso em 14 de julho de 2019.

FAULIN, Evandro Jacóia e AZEVEDO, Paulo Furquim de. Distribuição de hortaliças na agricultura familiar: uma análise das transações. Informações Econômicas, São Paulo, v.33, n.11, nov. 2003. Disponível em: http://www.iea. sp.gov.br/out/publicacoes/pdf/tec3-1103.pdf. Acesso em 02 de agosto de 2019.

GRAU, Eros Roberto. O Estado, a Liberdade e o Direito Administrativo. In: Crítica Jurídica. Revista Latino Americana de Política, Filosofia y Derecho. Número 21, Jul-dez/2002. Disponível em: https://constitucionalismodemocratico. direito.ufg.br/up/332/o/Cr\%C3\%ADtica_Juridica_na_America_Latina.pdf. Acesso em 15 de setembro de 2018.

GRISA, Catia; SCHNEIDER, Sergio. Três gerações de políticas públicas para a agricultura familiar e formas de interação entre sociedade e estado no Brasil. Rev. Econ. Sociol. Rural, Brasília , v. 52, supl. 1, p. 125-146, 2014. Disponível em: <http://www.scielo.br/scielo.php?script=sci_arttext\&pid=S0103$20032014000600007 \& \operatorname{lng}=$ en\&nrm=iso >. Acesso em 15 de julho de 2019.

LAKATOS, Eva e Marconi, Marina. Metodologia do Trabalho Científico. São Paulo: Atlas, 1992.

LIBERMANN, Angelita Pinto; BERTOLINI, Geysler Rogis Flor. Tendências de pesquisa em políticas públicas: uma avaliação do Programa Nacional de Alimentação Escolar - PNAE. Ciênc. saúde coletiva, Rio de Janeiro , v. 20, n. 11, p. 3533-3546, Nov. 2015 . Disponível em: <http://www.scielo.br/scielo. php?script=sci_arttext\&pid=S1413-81232015001103533\&lng=en\&nrm=iso >. Acesso em 14 de julho de 2019.

MANJINSKI, Everson. Manual da Monografia Jurídica: teoria, método e normas. São Paulo: Ferrariweb, 2004.

MARQUES, P.V.; MELLO, P. C. de e MARTINES J.G.. Mercados Futuros e de Opções Agropecuárias. Piracicaba, São Paulo Departamento de Economia, Administração e Sociologia da Esalq/USP, 2006, Série Didática no D-129. Disponível em: http://economia.esalq.usp.br/did/did-129.pdf. Acesso em 03 de agosto de 2019. 
MEIRELLES, Hely Lopes. Direito administrativo brasileiro. 24. ed. São Paulo, RT, 2004.

MELLO, Celso Antônio Bandeira de. Curso de direito administrativo. 8. ed. São Paulo, Malheiros, 1996.

PAGLIUCA, Larissa Gui; ARAÚJO, Lucas Conceição; GENESELI, Patrícia e TANUS, Tárik Cannan Thomé. Qual a melhor época para a venda de HFs? HF Brasil, no 9, fev. 2015. Disponível em: http://www.hfbrasil.org.br/br. Acesso em 02 de agosto de 2019.

PINHEIRO, Armando Castelar. Segurança jurídica, crescimento e exportações. Rio de Janeiro: Ipea, 2005. Disponível em: http://www.en.ipea.gov.br/agencia/ images/stories/PDFs/TDs/td_1125.pdf. Acesso em 10 de julho de 2019.

SCHIMITT, C. J. GUIMARÃES, L. A. O mercado institucional como instrumento para o fortalecimento da agricultura familiar de base ecológica. Revista Agriculturas - v. 5 - n. 2 - junho de 2008. Disponível em: http://www. agriculturesnetwork.org/magazines/brazil/equidade-e-soberania-nosmercados/ o-mercado-institucional-como-instrumento-para-o/at_download/article_pdf. Acesso em 15 de julho de 2019.

SILVA, Márcio Gomes da; DIAS, Marcelo Miná; SILVA, Sandro Pereira. Relações e estratégias de (des)envolvimento rural: políticas públicas, agricultura familiar e dinâmicas locais no município de Espera Feliz (MG). Rev. Econ. Sociol. Rural, Brasília , v. 52, n. 2, p. 229-248, Jun 2014 . Disponível em: <http://www.scielo.br/ scielo.php?script=sci_arttext\&pid=S0103-20032014000200002\&lng=en\&nrm=i so>. Acesso em 14 de julho de 2019.

SOUZA-ESQUERDO, Vanilde Ferreira de; BERGAMASCO, Sonia Maria Pessoa Pereira. Análise sobre o acesso aos programas de políticas públicas da agricultura familiar nos municípios do circuito das frutas (SP). Rev. Econ. Sociol. Rural, Brasília , v. 52, supl. 1, p. 205-222, 2014 . Disponível em: <http://www. scielo.br/scielo.php?script=sci_arttext\&pid=S0103-20032014000600011\&lng=en \&nrm=iso>. Acesso em 14 de julho de 2019.

TRICHES, Rozane Marcia; SCHNEIDER, Sergio. Alimentação escolar e agricultura familiar: reconectando o consumo à produção. Saude soc., São Paulo, v. 19, n. 4, p. 933-945, Dec. 2010 . Disponível em: <http://www.scielo.br/scielo. php?script=sci_arttext\&pid=S0104-12902010000400019\&lng=en\&nrm=iso >. Acesso em 14 de julho de 2019.

VENOSA, Sílvio de Salvo. Direito Civil: Contratos, v.3 - 14a ed. São Paulo: Atlas. 2014

WAQUIL, Paulo Dabdab; MIELE, Marcelo e SCHULTZ, Glauco. Mercados e comercialização de produtos agrícolas. Porto Alegre, Editora da UFRGS, 2010.

Aceito: 23/10/2019.

Submetido: 15/07/2019. 


\title{
INSTITUTIONAL ACQUISITION OF FAMILY AGRICULTURE PRODUCTS: NOTES ON OPERATIONAL ASPECTS OF PUBLIC POLICY
}

\begin{abstract}
The recognition given to family farming and the construction of differentiated policies for a social group that until then had not been contemplated with specific actions on the part of the Government certainly represents an important advance in the model of Democratic State of Law. The Food Acquisition Program (PAA) and the National School Feeding Program (PNAE) strengthen family farming with yet another marketing, diversification and income generation alternative, in addition to ensuring food and nutritional security for the population to whom food are intended. However, the policy of facilitating public procurement for family farmers may not be successful if it is complex in its execution and does not pay attention to the peculiarities of the sector regarding the definition of prices and the management of risks inherent to agricultural production. In view of this, the present work proposes an analysis of the guidelines for the definition of contractual prices in public purchases of products from family farming and to verify whether the legal hypotheses that authorize the contractual review are consistent with the reality of agricultural production, subject, by nature, to the risk of significant price fluctuations, difficult to predict, in order to contribute to the reflection of the current model and to the sustainability of these public policies.
\end{abstract}

Keywords: Agriculture. Institutional purchases. Risk management.

\section{ADQUISICIÓN INSTITUCIONAL DE PRODUCTOS DE AGRICULTURA FAMILIAR: NOTAS SOBRE ASPECTOS OPERATIVOS DE LA POLÍTICA PÚBLICA}

\begin{abstract}
Resumen
El reconocimiento otorgado a la agricultura familiar y la construcción de políticas diferenciadas para un grupo social que hasta entonces no había sido contemplado con acciones específicas por parte del gobierno ciertamente representa un avance importante en el modelo del Estado de Derecho Democrático. El Programa de Adquisición de Alimentos (PAA) y el Programa Nacional de Alimentación Escolar (PNAE) fortalecen la agricultura familiar con otra alternativa más para la comercialización, diversificación y generación de ingresos, además de garantizar la seguridad alimentaria y nutricional de la población a quien están destinados. Sin embargo, la política de facilitar la contratación pública de los agricultores familiares puede no tener éxito si es compleja en su ejecución y no presta atención a las peculiaridades del sector en términos de fijación de precios y gestión de los riesgos inherentes a la producción agrícola. En vista de esto, el presente trabajo propone un análisis de las pautas para la definición de precios contractuales en las compras públicas de productos de la agricultura familiar y para verificar si las hipótesis legales que autorizan la revisión contractual son consistentes con la realidad de la producción agrícola, sujeto, por naturaleza, al riesgo de fluctuaciones de precios significativas, difíciles de predecir, para contribuir a la reflexión del modelo actual y a la sostenibilidad de estas políticas públicas.
\end{abstract}

Palabras clave: Agricultura. Compras institucionales. Gestión de riesgos. 